\title{
Determinação dos clubes de convergência da renda per capita agrícola - uma análise para os municípios cearenses
}

\author{
José Nilo de Oliveira Junior ${ }^{1}$ \\ Marcelo Bentes Diniz ${ }^{2}$ \\ Ivan Castelar ${ }^{3}$ \\ Roberto Tatiwa Ferreira ${ }^{4}$
}

Resumo: Este artigo analisa o processo de convergência do valor da produção agrícola dos municípios cearenses utilizando um modelo com efeito threshold no período de 1970 a 1996. Os resultados mostraram a existência de quatro clubes de convergência. Um formado pelo grupo de municípios mais ricos, outro formado pelo grupo de municípios mais pobres e dois grupos intermediários. Os resultados intra-clubes indicam que tanto o capital humano como o capital físico são importantes na explicação do processo de crescimento da agricultura cearense. Já os resultados para a terra mostraram que este fator é importante apenas para os dois clubes mais ricos.

Palavras-chaves: setor agrícola cearense, convergência municipal, modelo threshold.

Abstract: This paper analyzes the process of agricultural county convergence in the state of Ceara using a threshold model in the period from 1970 to 1996. The results show the existence of four clubs of convergence. One formed by the group of richer counties; another one by the group of poor counties and two intermediate groups. The results intra-clubs show that both human capital and physical capital are important to explain the growth process of Ceara's agriculture. On the other hand land is important only for the two richer clubs.

Key-words: Ceará's agricultural sector, county convergence, threshold model.

Classificação JEL: Q19, O49, C21.

${ }_{1}^{1}$ Programa de Pós-Graduação em Economia, Universidade Federal do Pará (PPGEconomia/UFPA), Brasil. Email: joseniloojr@yahoo.com.br

${ }^{2}$ Programa de Pós-Graduação em Economia, Universidade Federal do Pará (PPGEconomia/UFPA), Brasil. Email: mbdiniz2007@hotmail.com

${ }^{3}$ Programa de Pós-Graduação em Economia, Universidade Federal do Ceará (CAEN/UFC), Brasil.

${ }^{4}$ Programa de Pós-Graduação em Economia, Universidade Federal do Ceará (CAEN/UFC), Brasil. E-mail: rtf2@uol.com.br 
- Determinação dos clubes de convergência da renda per capita agrícola: uma análise para os municípios cearenses

\section{Introdução}

A hipótese da convergência pode assumir três formas distintas: i) a hipótese da Convergência Absoluta - onde as rendas per capita dos países convergiriam entre si em longo prazo, independentemente de suas condições iniciais; ii) a hipótese da Convergência Condicional - onde as rendas per capita dos países convergiriam em longo prazo entre os países de características estruturais idênticas, independentemente de suas condições iniciais; iii) a hipótese de Clubes de Convergência - onde haveria a formação de grupos de países com as mesmas características estruturais e cada grupo teria um padrão próprio de crescimento. Esta última hipótese caracterizaria a persistência da pobreza, da polarização e da divisão de países em grupos (GALOR, 1996).

Além do trabalho de Galor (1996), nos estudos de Durlauf e Johnson (1995) e Rappaport (1999), a heterogeneidade entre as regiões pode gerar um processo de crescimento econômico caracterizado por múltiplos estados estacionários. Isto geraria grupos onde a renda per capita convergiria ao redor de um pequeno número de estados estacionários comuns, dependendo das condições iniciais de cada região específica.

Nesse sentido, o estudo de crescimento econômico é particularmente importante por várias razões. Primeiro porque propicia identificar padrões que permitem visualizar as trajetórias das rendas das economias. Segundo porque pode indicar as possíveis causas de trajetórias bem sucedidas de crescimento, dando lugar a ações de políticas públicas com vista a corrigir possíveis desequilíbrios e desigualdades.

Deste modo, este artigo tem como escopo analisar o setor agrícola dos municípios cearenses, de 1970 a 1996, com o intuito de investigar se existem evidências de múltiplos regimes ou clubes de convergência entre os municípios; se existe evidência de convergência intraclubes; e, ainda, se existe associação espacial entre esses clubes.

As três décadas que compreendem o período de análise testemunharam várias mudanças estruturais que marcaram indelevelmente o desenvolvimento agrícola no Brasil. A década de 1970 foi marcada pela implementação de grandes planos de desenvolvimento nacional e por choques externos como o do petróleo, crescimento da dívida externa e, conseqüentemente, pela crise na balança de pagamentos. Por sua vez, a década de 1980 foi marcada por mudanças políticas, descontrole inflacionário, fracassos dos diversos planos econômicos e, principalmente, pelo acirramento do problema da dívida externa. Por fim, a década de 1990 foi caracterizada pela abertura comercial, estabilização dos preços e pela expansão das exportações brasileiras, culminando com a criação de um novo padrão econômico no país (BRUM, 2003). 
A fim de alcançar os objetivos propostos, utilizou-se um modelo com efeito limiar (threshold), baseado em Hansen (2000), bem como dados censitários agrícolas do IBGE (Instituto Brasileiro de Geografia e Estatística). Tal modelo permite testar estatisticamente e identificar os subgrupos de municípios com características comuns quanto ao processo de convergência; isto é, convergência para regimes múltiplos.

Este processo de identificação poderia, por exemplo, ser realizado através do algoritmo da árvore de regressões, utilizado por Durlauf e Johnson (1995). Entretanto, enquanto a técnica de árvore de regressões possui um caráter ad hoc, não apresentando uma estatística de teste com uma distribuição conhecida, a principal vantagem da metodologia desenvolvida por Hansen é a existência de uma estatística de teste fundamentada na teoria assintótica. Ademais, o comportamento dessa estatística em pequenas amostras já foi suficientemente estudado através de simulações de Monte Carlo.

Além desta introdução, o artigo se divide em mais 5 seções. A seção 2 trata da revisão da literatura sobre o tema proposto; a seção 3 traz uma análise da economia rural cearense; a seção 4 apresenta o modelo teórico utilizado; a seção 5 descreve a metodologia econométrica empregada no trabalho; a seção 6 traz os resultados empíricos e, por fim, a seção 7 trata das conclusões.

\section{Revisão da Literatura}

Desde o trabalho de Baumol (1986), que concluiu pela existência de convergência entre países industrializados, o estudo da convergência entre países tem sido um tema de pesquisa controvertido. De Long (1988) contesta as conclusões de Baumol apontando, entre outros defeitos, o viés de seleção dos países analisados.

Em um clássico sobre convergência, Barro e Sala-i-Martin (1992) detectam convergência absoluta entre os estados americanos de 1840 a 1988 . No entanto, com dados transversais para um grupo de 110 países, somente foi detectada convergência condicional entre 1960 e 1985. Sala-i-Martin (1996) obtém os mesmos resultados para o mesmo grupo de 110 países no período de 1960 a 1990, porém encontra convergência absoluta para uma subamostra de países da OECD (Organização para a Cooperação e Desenvolvimento Econômico); $\beta$-convergência absoluta e condicional, bem como $\sigma$-convergência, para os estados dos EUA, prefeituras do Japão e para as regiões da Alemanha, Reino Unido, França, Itália e Espanha, respectivamente.

Já em relação à classe de modelos de crescimento endógeno, destacam-se os trabalhos de Lucas (1988) e Romer (1986). O primeiro inclui na função de produção neoclássica o insumo capital humano, concebido como o estoque de conhecimento acumulado da população. Romer, por sua vez, abandonou a 
- Determinação dos clubes de convergência da renda per capita agrícola: uma análise para os municípios cearenses

hipótese de concorrência perfeita e retornos decrescentes dos fatores e postulou a existência de externalidades advindas do aprendizado adquirido no processo produtivo.

Após estes dois trabalhos, proliferou a literatura que associava o crescimento econômico ao nível educacional da sociedade. Destacam-se entre estes, por exemplo, os trabalhos de Baumol et al. (1989), os quais concluem que países com níveis educacionais semelhantes convergem mais rapidamente. Mankiw et al. (1992) verificaram que o nível de poupança, o crescimento populacional e o nível de educação explicam a maior parte da variação do crescimento econômico. Vale ressaltar que existe uma abundância de evidências empíricas que demonstram uma correlação positiva entre o nível de escolaridade e a taxa de crescimento, porém, a relação causal é questionada. Um exemplo desta corrente é Bills e Klenow (2000), os quais argumentam que o crescimento econômico é mais relevante para o nível educacional que o contrário.

Já com relação ao Brasil, vários são os trabalhos na área de convergência. Andrade (1997), analisando o período de 1970 a 1995, revela a importância do capital humano para o crescimento econômico regional. Ele estima que um ano adicional de estudo implica em 0,32\% de variação positiva do PIB. Zini Jr (1998) conclui, utilizando a série de Azzoni (1997), pela existência de fraca convergência absoluta e convergência condicional.

Azzoni et al. (2000) e Azzoni e Barossi (2003), utilizando dados em painel e séries temporais, concluem que existe uma fraca convergência do PIB per capita dos estados. Segundo estes autores, cinco estados se encontram em processo de convergência e três de fraca convergência, enquanto Amapá, Pará, Piauí, Santa Catarina e São Paulo não estão convergindo.

Vergolino e Monteiro Neto (1996) verificam a hipótese de convergência para as microrregiões nordestinas entre 1970 e 1993. Os autores identificam poucas evidências de convergência absoluta e apontam as capitais estaduais como agentes inibidores. Rocha e Vergolino (2001) estendem o período analisado a 1998, onde verificam a ocorrência de convergência absoluta na década de 1970, mas não encontram evidências para a década seguinte. Os autores apontam convergência condicional ao introduzirem capital humano, localização geográfica e condições de vida da população como variáveis estruturais.

Porto Jr. e Ribeiro (2000), além da metodologia usual de Barro, utilizaram matrizes de transição de Markov e estimação de funções densidades de probabilidade para analisar o processo de convergência entre os municípios da Região Sul de 1970 a 1991. Os autores constataram a formação de dois clubes de convergência entre os municípios. Porto Jr. e Souza (2002), utilizando matrizes de transição de Markov e testes de Drennam e Lobo, verificaram a inexistência de convergência entre os municípios da Região Nordeste entre 1970 e 1991. Constataram, ainda, a polarização na distribuição da renda per capita dos estados. 
Barreto e Gondim (2004) investigaram a convergência entre estados, mesorregiões, microrregiões e municípios. Considerando as unidades federativas, entre 1950 e 2000, os autores verificaram instabilidade no processo de convergência e concluem que a distribuição da renda per capita evolui ao longo do tempo para uma formação bi-modal em todos os níveis geográficos. Os autores encontraram, ainda, evidências robustas de convergência condicional quando a distribuição de renda per capita é condicionada no âmbito da escolaridade e da localização geográfica.

Marino (2004) analisou a hipótese de convergência entre as rendas per capita dos estados e dos municípios brasileiros, de 1970 a 2000, rejeitando a hipótese de convergência absoluta entre os estados. No entanto, constatou a polarização da renda per capita em dois clubes de convergência. $\mathrm{O}$ primeiro, formado pelos estados do Norte e Nordeste, e o segundo formado pelas unidades das regiões Sudeste, Sul e Centro-Oeste. Vale ressaltar que, nesse estudo, o capital humano e o grau de urbanização do município são as variáveis condicionantes de maior relevância para o processo de convergência.

No estudo de Magalhães (2001), o autor se propôs a verificar a existência de clubes de convergência entre os estados brasileiros, de 1986 a 1995, a partir de hiatos $^{5}$ de renda ${ }^{6}$. Os resultados preliminares para â-convergência entre os estados indicam a inexistência de um processo de convergência. Já os resultados para clubes de convergência indicaram a presença de dois clubes; constatando que o primeiro clube, formado pelos estados do Rio de Janeiro, Rio Grande do Sul e Minas Gerais, estaria convergindo para o nível de renda per capita de São Paulo; enquanto que o segundo clube, constituído por todos os estados do Nordeste e alguns do Norte, estaria divergindo.

Laurini et al. (2003) investigaram a existência de clubes de convergência de renda per capita para um total de 3.781 municípios entre 1970 e 1996. A metodologia utilizada foi a de matrizes de transição de Markov e núcleo estocástico. Os resultados de ambas as técnicas confirmaram a presença de dois clubes de convergência para renda per capita dos municípios no período em questão. Os resultados sugerem que a formação de clubes deve-se ao distanciamento uniforme da renda relativa das regiões Norte e Nordeste em relação aos valores das regiões Centro-Oeste, Sudeste e Sul.

Alencar (2005) investigou a importância das dotações iniciais de capital físico e capital humano para caracterizar o desempenho socioeconômico dos municípios do Brasil, bem como verificou a existência de clubes de convergência da renda per capita ao usar um modelo threshold. Nesse estudo, o autor fez uso de dados transversais entre 1980 e 2000 para um total de 4.786 municípios, usando a

\footnotetext{
${ }^{5}$ O hiato é entendido como o logaritmo da razão entre o estado de maior renda per capita (São Paulo) e o estado $i$.

${ }^{6}$ Foi utilizado como proxy para renda o PIB dos estados.
} 
1000 - Determinação dos clubes de convergência da renda per capita agrícola: uma análise para os municípios cearenses

dotação inicial da renda per capita e a taxa de analfabetismo para delimitar os clubes de convergência. Seus resultados mostram a existência de oito de clubes de convergência entre os municípios e constata convergência dentro de todos eles. Este autor conclui, ainda, que as dotações iniciais de capital humano são mais importantes para o processo de crescimento da renda per capita do que as dotações iniciais de capital físico.

Gondim et al. (2007) verificaram os principais condicionantes dos clubes de convergência no Brasil. Para tanto, utilizaram a metodologia de Quah para a renda condicionada de estados e municípios entre 1970 e 2000, dividida em nove classes de tamanho fixo. Os condicionantes utilizados foram: localização geográfica, escolaridade, abertura comercial e desigualdade de renda. Os resultados, tanto para os estados como para os municípios, indicam a formação de dois clubes de convergência. $\mathrm{O}$ maior clube é formado por unidades com renda baixa; e outro, menor, formado por unidades com renda alta. Quanto aos condicionantes, os resultados indicam, tanto para estados como para municípios, que o nível de escolaridade e a localização geográfica seriam fatores importantes na formação desses clubes. Por outro lado, a maior integração ao comércio internacional e a desigualdade da renda não parecem ter influência sobre a desigualdade regional no Brasil.

Oliveira Júnior et al. (2007) investigaram a hipótese de clubes convergência da renda agrícola entre as microrregióes do Brasil usando dados dos censos agrícola de 1970 a 1995 e um modelo threshold. Os resultados apontam a formação de três clubes de convergência: um clube mais rico formado por microrregiões do Sul e Sudeste, um clube intermediário formado, principalmente, pelas microrregiões do Norte e Centro-Oeste e, por fim, um clube mais pobre formado pelas microrregiões do Nordeste. Os resultados também mostraram que o capital físico é mais importante que o capital humano na explicação do processo de crescimento da agricultura brasileira.

Constata-se nos diversos trabalhos sobre a hipótese de convergência para o Brasil, nos diversos períodos de análise, que existem algumas conclusões coincidentes. Observa-se, entre os estados brasileiros, que o processo de convergência é instável e fraco. Em relação aos municípios, não obstante o pequeno número de trabalhos, a literatura aponta para a divergência e a polarização. Há ainda fortes evidências da formação de dois pólos, seja de estados ou municípios, com características socioeconômicas diferentes. Percebe-se, assim, que ao contrário dos países desenvolvidos, as desigualdades regionais brasileiras são extremamente persistentes. 


\section{Uma Descrição da Economia do Estado do Ceará}

\subsection{Análise dos Indicadores de Educação do Estado do Ceará}

O estado do Ceará vem melhorando seus indicadores econômicos e sociais ao longo dos últimos anos, principalmente quando se observa a evolução da educação. Analisando a Figura 1, a seguir, e considerando a evolução do IDH (Índice de Desenvolvimento Humano), tendo como referência a educação ${ }^{7}$, observa-se que o estado acompanha a trajetória de crescimento do índice nacional, bem como as dos demais estados da região Nordeste.

Esta variável indica que as políticas sociais implementadas no estado ao longo dos últimos 30 anos têm sido eficazes no que diz respeito ao aumento da alfabetização e freqüência escolar, o que implica no aumento da qualificação da população cearense e que pode, em linhas gerais, fomentar maior dinamismo no crescimento econômico.

Figura 1. Evolução do Índice de Desenvolvimento Humano (IDH) - Educação

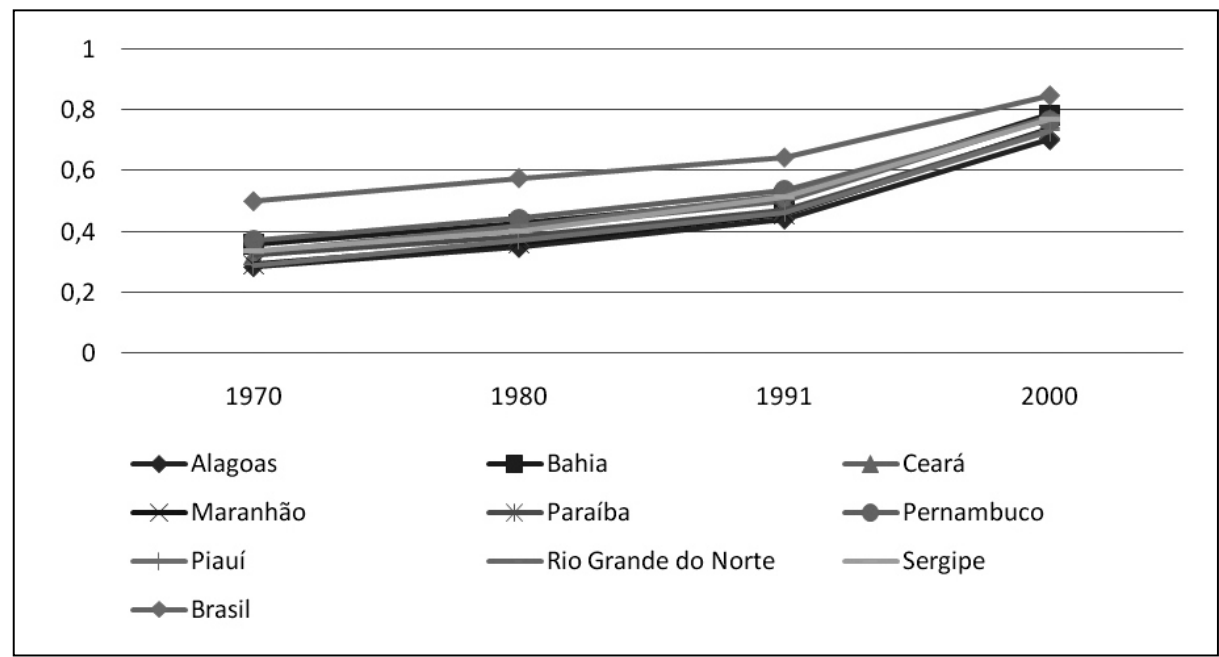

Fonte: IPEADATA. Elaboração dos Autores.

\footnotetext{
$\overline{7}$ O IDH relativo à educação é obtido a partir da taxa de alfabetização e da taxa bruta de freqüência à escola, convertidas em índices por: (valor observado - limite inferior) / (limite superior - limite inferior), com limites inferior e superior de $0 \%$ e $100 \%$. O IDH-Educação é a média desses 2 índices, com peso 2 para o da taxa de alfabetização e peso 1 para o da taxa bruta de freqüência.
} 
1002 - Determinação dos clubes de convergência da renda per capita agrícola: uma análise para os municípios cearenses

Esta melhora nos indicadores de educação pode ser observada também no âmbito municipal, uma vez que os anos médios de estudo vêm crescendo ao longo das últimas três décadas, sobretudo, no interior do estado. As Figuras 2 e 3 foram criadas utilizando os dados do Atlas do Desenvolvimento Humano, no qual se pode fazer a comparação da dispersão das médias dos anos de estudo entre municípios.

Na Figura 2, utilizando dados da média de anos de educação em 1991, pode-se observar que apenas cerca de 40 municípios apresentam população com mais de dois anos de estudos e estes estão concentrados principalmente em torno das grandes cidades como Fortaleza, Itapipoca, Sobral e Juazeiro do Norte. Os municípios em condições mais críticas concentram-se principalmente nas regiões Norte e Sudoeste do estado.

Já quando os mesmos dados são observados em 2000, na Figura 3, apresenta-se uma nova realidade, principalmente no interior, uma vez que o número de municípios com população com mais de dois anos de estudo é agora de 145, restando apenas cerca de 38 municípios que possuem menos de dois anos de estudo médios. Novamente, as regiões em situações mais críticas são as regiões Norte e Sudoeste do estado. Portanto, os dados mostram uma evolução considerável em termos de educação no estado, principalmente, considerando o interior.

Figura 2. Média de Anos de Estudo de Pessoas com 25 anos ou mais, 1991
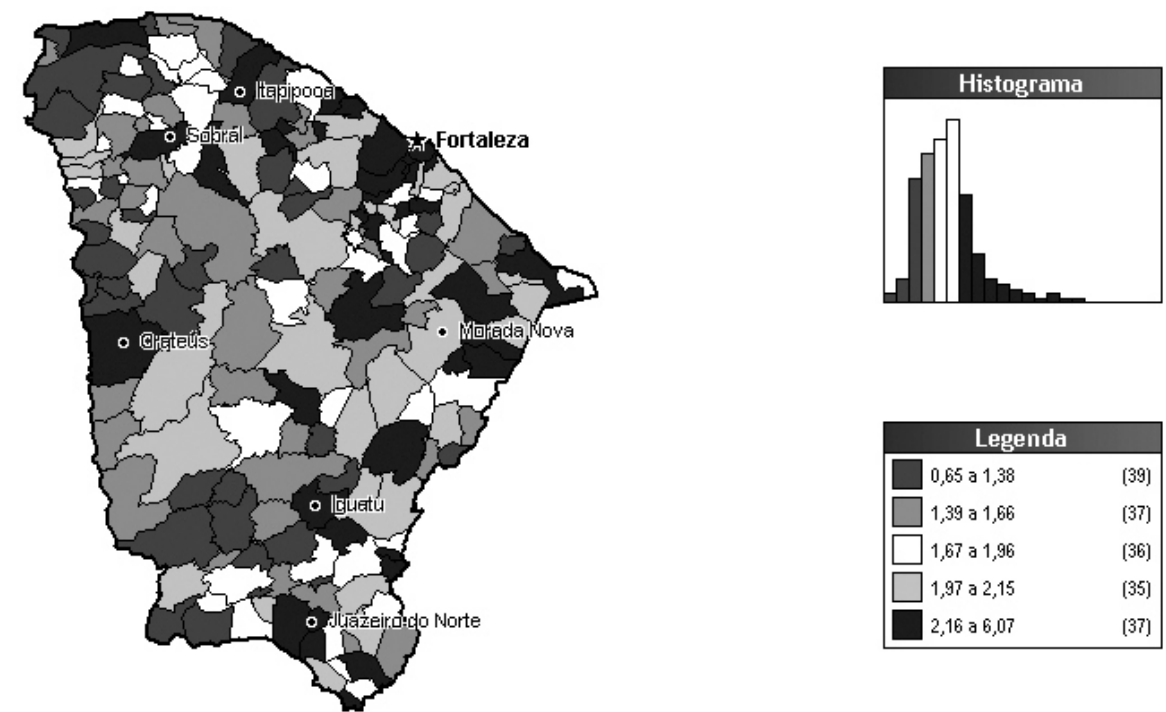

Fonte: Atlas do Desenvolvimento Humano. Elaboração dos autores.

\begin{tabular}{|ll|}
\hline \multicolumn{2}{|c|}{ Legenda } \\
\hline$\square 0,65$ a 1,38 & $(39)$ \\
$\square 1,39$ a 1,66 & $(37)$ \\
$\square 1,67$ a 1,96 & $(36)$ \\
$\square 1,97$ a 2,15 & $(35)$ \\
& $(37)$ \\
\hline 2,16 a 6,07 & \\
\hline
\end{tabular}


Figura 3. Média de anos de estudo de pessoas com 25 anos ou mais, 2000
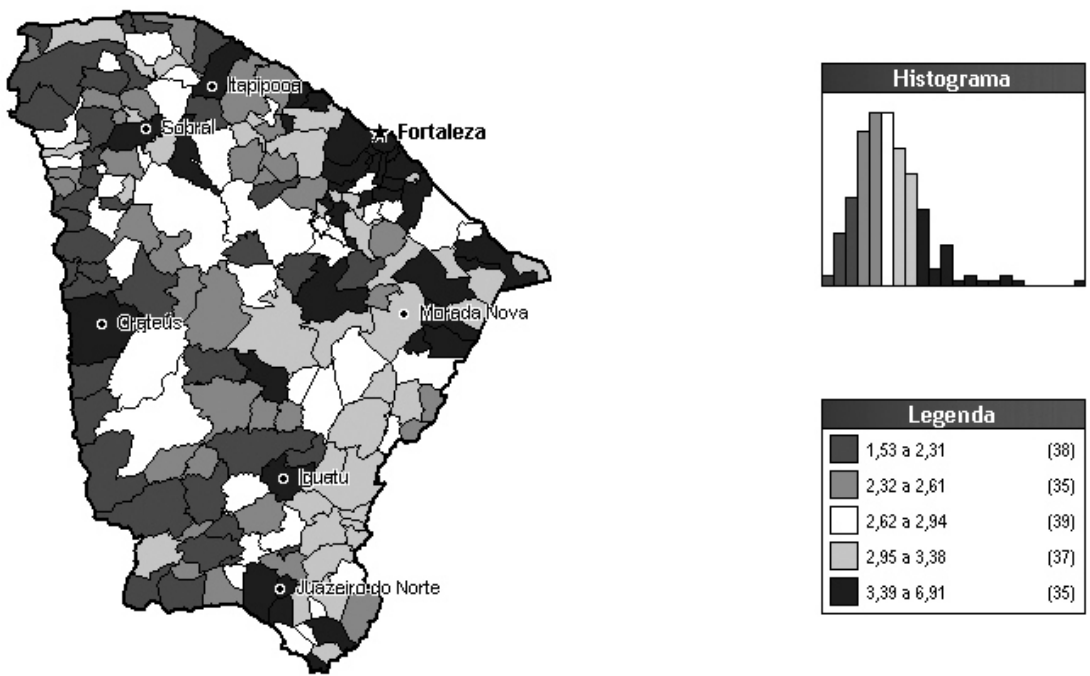

Fonte: Atlas do Desenvolvimento Humano. Elaboração dos autores.

\subsection{O Setor Rural Cearense}

A Tabela 1 traz uma descrição socioeconômica do setor rural do estado do Ceará, tendo como base os dados dos Censos Agropecuários de 1970 - 1995/1996, bem como os dados do Censo Demográfico de 2000.

Pode-se observar, em linhas gerais, que a renda ${ }^{8}$ per capita média em 1970 no setor era de R \$ 789,29, passando para R \$1.211,61 em 1995/96, o que corresponde a uma variação positiva de $34,85 \%$ no período. Em termos de educação, a média de anos de estudo para o conjunto de microrregiões em 2000 era de 3,08 com um desvio-padrão de 0,765 .

Verifica-se, também, que a microrregião de Fortaleza apresentou maior renda per capita tanto em 1970 quanto em 1995/96, de R\$3.145,48 e R\$ 4.567,13, respectivamente, com taxa de crescimento de cerca de $40 \%$ no período. A referida microrregião também registrou o melhor indicador de educação, com mais de seis anos de estudo, em média. No entanto, a microrregião possui apenas 25.013 pessoas ocupadas, enquanto a média do estado é de 36.143.

Já a última microrregião no rank, Litoral do Aracati, apresenta uma renda per capita de R\$377,38 em 1970, que é 10 vezes menor que a renda per capita da microrregião de Fortaleza no mesmo ano. No entanto, em 1995/96, a renda per capita da referida microrregião passou a ser de $\mathrm{R} \$ 2.129,25$, o que equivale a um crescimento de $173 \%$ no período de análise.

\footnotetext{
${ }^{8}$ Valores em reais de 2000, deflacionados pelo Deflator Implícito do PIB Nacional. A variável foi construída dividindo o valor da produção agropecuária pelo total da população ocupada no meio rural.
} 
1004 - Determinação dos clubes de convergência da renda per capita agrícola: uma análise para os municípios cearenses

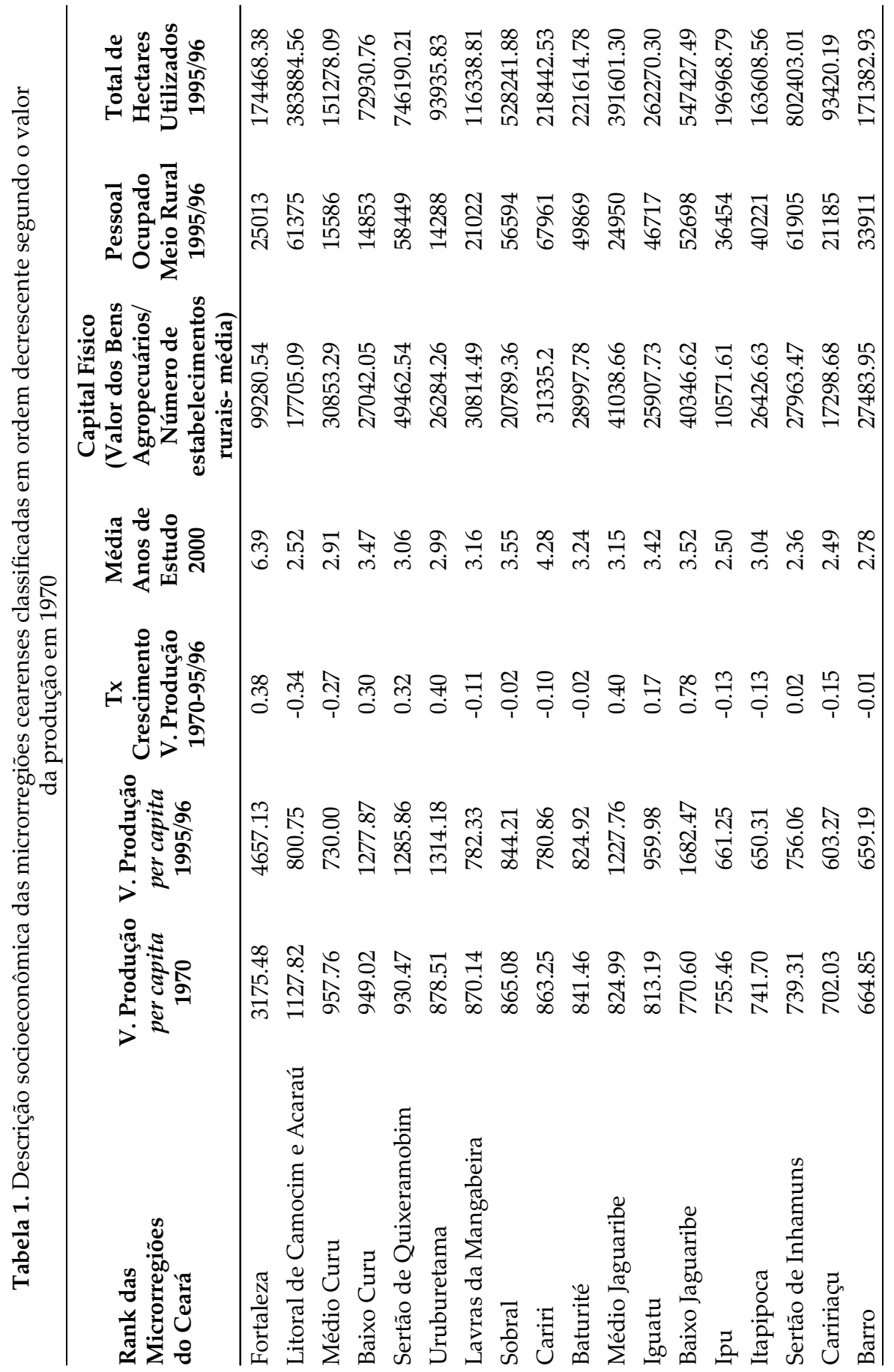

RESR, Piracicaba, SP, vol. 47, no 04, p. 995-1021, out/dez 2009 - Impressa em dezembro 2009 


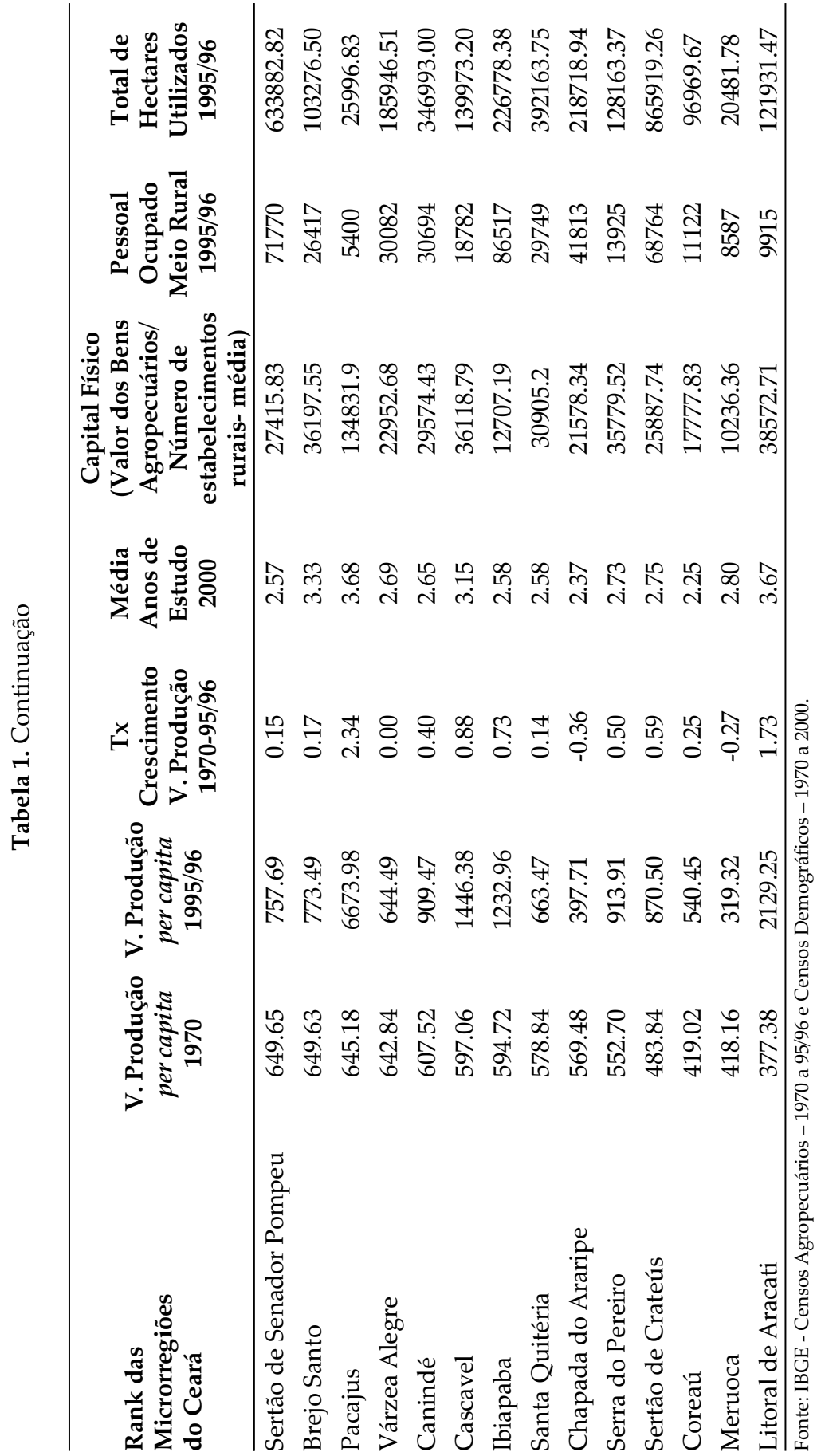

RESR, Piracicaba, SP, vol. 47, no 04, p. 995-1021, out/dez 2009 - Impressa em dezembro 2009 
1006 - Determinação dos clubes de convergência da renda per capita agrícola: uma análise para os municípios cearenses

Com relação ao capital físico ${ }^{9}$, pode-se observar na Tabela 1 que existe uma grande heterogeneidade quanto ao volume de estoque pertencente às microrregiões. A microrregião de Fortaleza destaca-se como a microrregião com maior estoque, representando cerca de 9,5\% do estoque estadual, seguida das microrregiões de Sertão de Quixeramobim, Médio Jaguaribe, Baixo Jaguaribe e Litoral do Aracati, com 4,66\%, 3,87\%, 3,80\% e 3,63\%, respectivamente.

Ainda com relação ao capital físico, a Figura 4 mostra que o volume de investimentos realizados no ano no setor em nível de mesorregião cresceu até 1980 quando houve uma reversão dessa tendência. Já com relação ao número de tratores nessas mesorregiões, observa-se que existe uma tendência de crescimento comum a todas, liderada pela mesorregião do Sul Cearense.

Figura 4. Evolução dos investimentos anuais no setor rural e evolução do número de tratores das mesorregiões do estado do Ceará, 1970 - 95/96

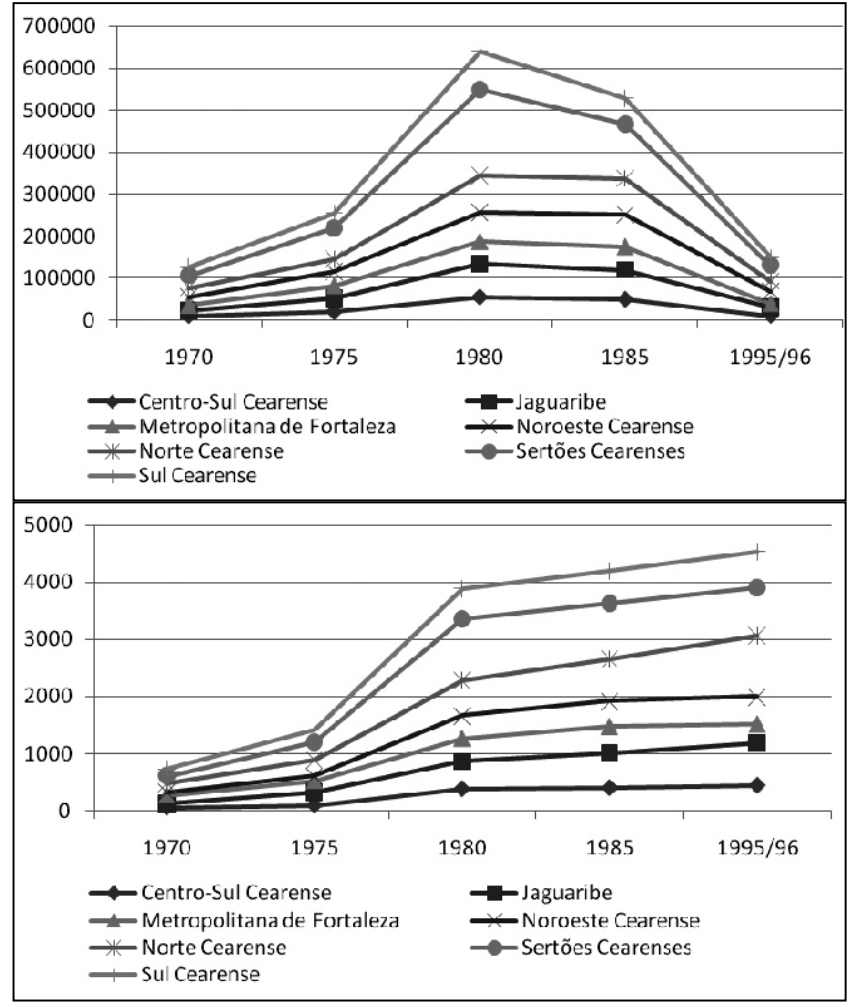

Fonte: IBGE - Censos Agropecuários 1970 - 95/96.

${ }_{9}^{9}$ Valores em reais de 2000, deflacionados pelo Deflator Implícito do PIB Nacional. A variável foi construída dividindo o valor médio dos bens pelo número total de estabelecimentos rurais. 
Quanto à distribuição da terra, pode-se observar pelo índice de Gini ${ }^{10}$ (SOUZA; LIMA, 2003) e seguindo a convenção ${ }^{11}$ estabelecida por Câmara (1949) que o Brasil e os estados da Bahia, Alagoas, Paraíba, Rio Grande do Norte, Pernambuco, Sergipe e Ceará apresentam a distribuição da terra com característica de concentração forte a muito forte. Já os estados do Piauí e Maranhão apresentam uma concentração de forte a absoluta. Portanto, os resultados apontam uma grande concentração da terra nos estados da região Nordeste (Figura 5).

Figura 5. Índice de Gini da distribuição da terra para o Brasil e para os estados da região Nordeste, 1970 - 95/96

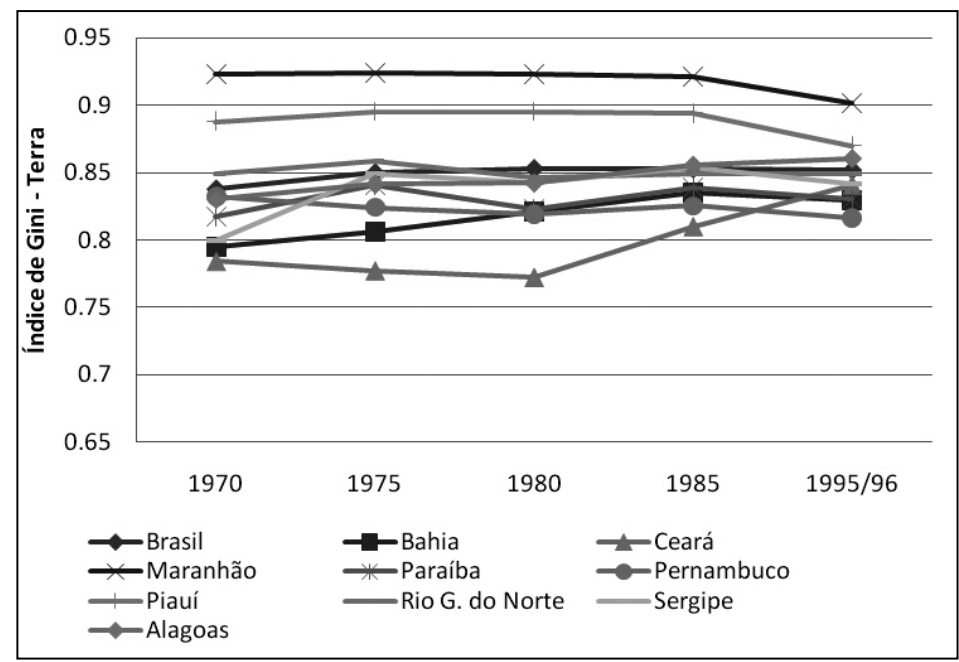

Fonte: Souza e Lima (2003).

\footnotetext{
${ }^{10}$ A definição índice de Gini pode ser dada pela curva de Lorenz. Seja o p o valor proporção acumulado da população até certo estrato e $\Phi$ o valor correspondente à proporção acumulada da posse da terra. Os pares de valores $(p, \Phi)$, para os diversos estratos, irão definir um conjunto de pontos, cuja união constitui a curva de Lorenz, que mostra como a proporção acumulada da posse da terra varia em função da proporção acumulada de proprietários, com os indivíduos ordenados de acordo com valores crescentes de tamanho das propriedades (HOFFMANN, 1991).

${ }^{11}$ A classificação das faixas do índice de Gini segue a seguinte classificação: de 0-0,100, concentração nula; $0,101-0,250$, concentração nula a fraca; $0,251-0,500$, concentração fraca a média; $0,501-0,700$, concentração média a forte; $0,701-0,900$, concentração forte a muito forte e, 0,901-1,00, concentração muito forte a absoluta.
} 
1008 - Determinação dos clubes de convergência da renda per capita agrícola: uma análise para os municípios cearenses

Ainda com relação à distribuição da posse da terra, a Figura 6 traz os indicadores da área média em hectares, o percentual da área correspondente a $50 \%$ dos menores estabelecimentos e o percentual correspondente a $5 \%$ dos maiores estabelecimentos para o estado do Ceará, segundo dados dos Censos Agropecuários de 1970-95/96.

Vê-se que a área média dos estabelecimentos apresentou comportamento cíclico, decaindo principalmente após 1980. Quanto ao comportamento do percentual da área correspondente a 50\% dos menores estabelecimentos, pode-se verificar que o mesmo apresentou elevação durante 1970 e 1980, decaindo desse período em diante. Já o percentual da área relativa a 5\% dos maiores estabelecimentos apresentou declínio até 1980 e crescimento após esta década. Portanto, os resultados permitem concluir que no período de análise houve um aumento na concentração da terra no estado do Ceará, uma vez que os menores estabelecimentos perderam participação em favor dos maiores estabelecimentos.

Figura 6. Área média em hectares, percentual da área correspondente aos $50 \%$ menores estabelecimentos e o percentual correspondente aos

5\% maiores estabelecimentos para o estado do Ceará, 1970 - 95/96

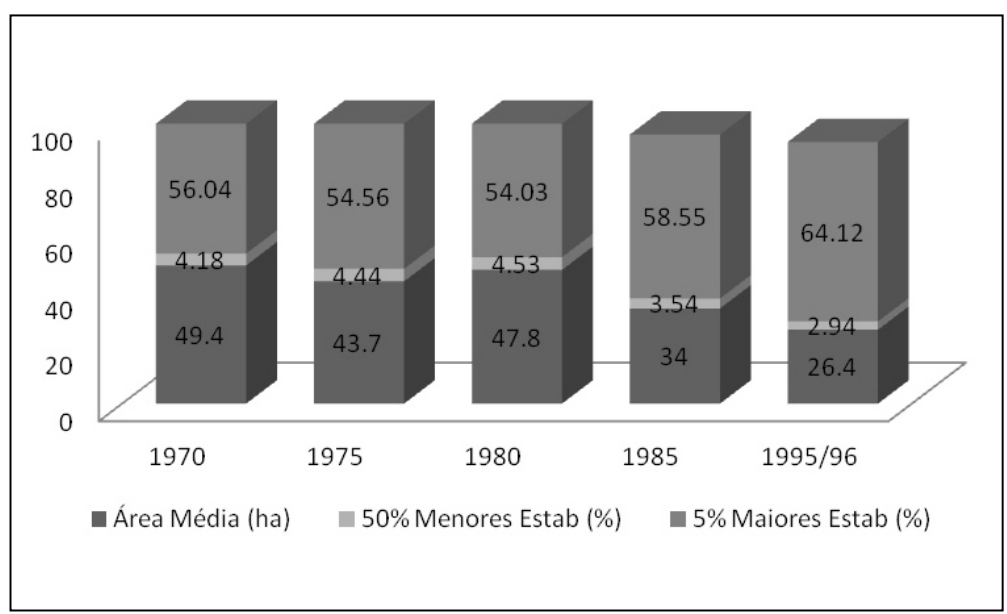

Fonte:IBGE - Censos Agropecuários 1970 - 95/96.

Quanto às principais culturas do estado em 2007, a Figura 7 mostra que as três principais atividades da agricultura são milho, feijão e castanha de caju, com total de área plantada, em hectares, de 679400, 561220 e 376141, respectivamente. Além dessas, possuem ainda certo destaque as culturas de mandioca, coco, cana-de-açúcar, banana e arroz. 
Figura 7. Área destinada à colheita/plantada dos principais produtos das culturas permanentes e temporárias, segundo os municípios - Ceará -2007

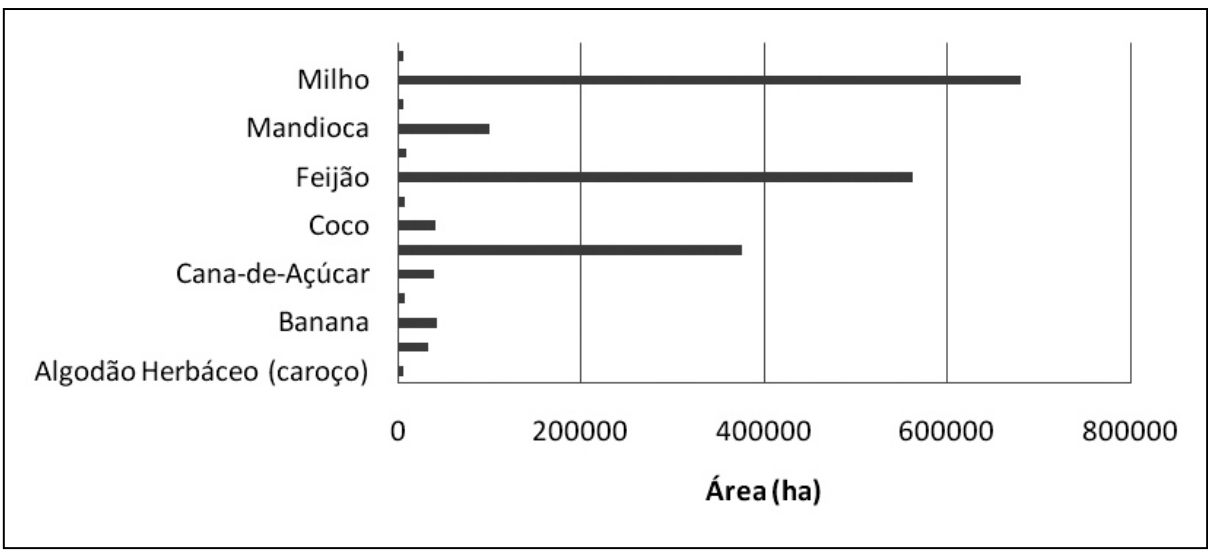

Fonte: Instituto Brasileiro de Geografia e Estatística (IBGE), Produção Agrícola Municipal 2005-2006 e Levantamento Sistemático da Produção Agrícola 2007.

Portanto, as diferenças de renda entre as microrregiões do estado, o comportamento cíclico da área média de terras utilizadas, a posse heterogênea do estoque de capital físico, bem como o aumento da participação dos grandes estabelecimentos em detrimento dos pequenos, reforça a idéia da existência de diferentes grupos de municípios com características diferenciadas.

\section{Análise Teórica de Múltiplos Regimes ou Clubes de Convergência}

\subsection{Modelo de Solow Aumentado}

A metodologia empregada baseia-se em Alencar (2005), o qual segue os modelos de Mankiw et al. (1992) e Durlauf e Johnson (1995). O modelo considera que a renda agrícola do município $i$ no tempo $t\left(Y_{i, t}\right)$ é determinado por uma função de produção do tipo Cobb-Douglas, que tem como argumentos a tecnologia, $\left(A_{i, t}\right)$; o trabalho, $\left(L_{i, t}\right)$; o capital físico $\left(K_{i, t}\right)$, o capital humano $\left(H_{i, t}\right)$ e a terra $\left(T_{i, t}\right)$; como mostra a equação abaixo.

$$
Y_{i, t}=\phi K_{i, t}^{\alpha} H_{i, t}^{\gamma} T_{i}^{\beta}\left(A_{t} L_{i, t}\right)^{1-\alpha-\gamma-\beta}
$$

Assume-se que todas as variáveis estão em tempo contínuo e que a tecnologia e a força de trabalho crescem a uma taxa constante, dadas por $g$ e $n_{i}$, respectivamente. Cada município multiplica seu estoque de capital físico e humano pela taxa de poupança, representadas por $s_{i}^{k}$ e $s_{i}^{h}$, enquanto ambos os estoques depreciam-se à 
1010 - Determinação dos clubes de convergência da renda per capita agrícola: uma análise para os municípios cearenses

mesma taxa $\delta$. Isto induz a equação de acumulação do capital da forma $d K_{i, t} / d t=s_{i}^{k} Y_{i, t}-\delta K_{i, t}$ e $d H_{i, t} / d t=s_{i}^{h} Y_{i, t}-\delta H_{i, t}$. Como resultado, sobre qualquer intervalo de $T$ a $T+\tau$, o produto por trabalhador segue a seguinte lei,

$$
\begin{aligned}
& \ln (Y / L)_{i, T+\tau}-\ln (Y, L)_{i, T}=g \tau+\left(1-e^{\lambda_{i r}}\right)\left(\Theta+\frac{\alpha}{1-\alpha-\gamma-\beta} \ln \left(s_{i}^{k}\right)+\right. \\
& \left.+\frac{\gamma}{1-\alpha-\gamma-\beta}\left(s_{i}^{h}\right)+\frac{\beta}{1-\alpha-\gamma-\beta}\left(T_{i}\right)-\frac{\alpha+\gamma+\beta}{1-\alpha-\gamma-\beta}\left(n_{i}+g+\delta\right)-\ln (Y / L)_{i, T}\right) \\
& \lambda_{i}=(1-\alpha-\gamma-\beta)\left(n_{i}+g+\delta\right)
\end{aligned}
$$

em que $\Theta=1 /(1-\alpha-\gamma-\beta) \ln \phi-\ln A_{T}-g T$ e $\lambda_{i}$ é a taxa de convergência em direção ao estado estacionário.

As equações (2) e (3) representam uma versão restrita do modelo de Solow, com uma restrição não linear entre os coeficientes da regressão. A fim de superar este problema, assume-se o mesmo valor da $\lambda_{i}$ para todos os municípios da amostra; o que, por sua vez, gera uma versão irrestrita do modelo de Solow do produto por trabalhador:

$$
\begin{aligned}
& \ln (Y, L)_{i, 1996}-\ln (Y, L)_{i, 1970}=\beta_{0}+\beta_{1} \ln (Y, L)_{i, 1970}+\beta_{2} \ln \left(s_{i}^{k}\right)+ \\
& +\beta_{3} \ln \left(s_{i}^{h}\right)+\beta_{4} \ln \left(T_{i}\right)-\beta_{5} \ln \left(n_{i}+g+\delta\right)+\varepsilon_{i}
\end{aligned}
$$

A evidência de convergência é associada com o sinal negativo para $-\left(1-e^{\lambda_{i t}}\right)$ no modelo restrito ou para $\beta_{1}$ no modelo irrestrito. A intuição é que a convergência ocorre quando economias com renda per capita baixa crescem mais rápido que economias com renda per capita alta.

\subsection{Evidências para Múltiplos Regimes ou Clubes de Convergência}

Na literatura contemporânea é comum observar modelos que são baseados na idéia de que podem existir funções de produção que não sejam côncavas, permitindo diferentes equilíbrios de estado estacionário para diferentes condições iniciais. Um destes modelos é o de Azariadis-Drazen (1990), que introduz um efeito limiar (threshold) no processo de acumulação de capital físico ou humano, de forma que

$$
Y_{i, t}=\phi K_{i, t}^{\alpha_{j}} H_{i, t}^{\gamma_{j}} T_{i}^{\beta}\left(A_{t} L_{i, t}\right)^{1-\alpha_{j}-\gamma_{j}-\beta}
$$

no qual

$$
\alpha_{j}=\left\{\begin{array}{l}
\alpha_{1} \text { se } K_{i, t}<\widetilde{K}_{t} \\
\alpha_{2} \text { caso contrário }
\end{array} \quad \text { e } \quad \gamma_{j}=\left\{\begin{array}{l}
\gamma_{1} \text { se } H_{i, t}<\widetilde{H}_{t} \\
\gamma_{2} \text { caso contrário }
\end{array}\right.\right.
$$


Este tipo de não-convexidade ${ }^{12}$, para alguns valores limiares de $\widetilde{H}_{t}$ e $\widetilde{K}_{t}$, gera múltiplos estados estacionários com a seguinte lei de formação,

$$
\begin{aligned}
& \ln (Y / L)_{i, T+\tau}-\ln (Y, L)_{i, T}=g r+\left(1-e^{\lambda_{i r}}\right)\left(\Theta_{j}+\frac{\alpha_{j}}{1-\alpha_{j}-\gamma_{j}-\beta} \ln \left(s_{i}^{k}\right)+\right. \\
& \left.+\frac{\gamma_{j}}{1-\alpha_{j}-\gamma_{j}-\beta}\left(s_{i}^{h}\right)+\frac{\beta}{1-\alpha_{j}-\gamma_{j}-\beta}\left(T_{i}\right)-\frac{\alpha_{j}+\gamma_{j}+\beta}{1-\alpha_{j}-\gamma_{j}-\beta}\left(n_{i}+g+\delta\right)-\ln (Y / L)_{i, T}\right)
\end{aligned}
$$

em que

$$
\lambda_{i, j}=\left(1-\alpha_{j}-\gamma_{j}-\beta\right)\left(n_{i}+g+\delta\right) \text { e } \Theta_{j}=1 /\left(1-\alpha_{j}-\gamma_{j}-\beta\right) \ln \phi-\ln A_{T}-g T
$$

Assim, os municípios irão seguir umas das quatro leis de formação distintas do Modelo de Solow, de acordo com o relacionamento entre $\left(K_{i, t}, H_{i, t}\right)$ e $(\widetilde{K}, \widetilde{H})$.

É importante observar que o modelo ilustrado acima encoraja a estratégia empírica adotada neste trabalho, o qual tem como principal objetivo analisar o comportamento dos subgrupos de municípios, identificados por dotações iniciais da renda agrícola per capita e seguindo diferentes tipos de regressões de crescimento de Solow.

\section{Metodologia}

\subsection{Modelo Threshold e Intervalo de Confiança}

A abordagem descrita abaixo é baseada em Hansen (2000), que desenvolveu um modelo que permite a divisão da amostra baseada em uma função indicadora, a qual utiliza variáveis observáveis, definidas previamente, como determinantes na divisão da amostra em subgrupos. As equações a seguir descrevem o modelo e as técnicas de inferência estatística necessárias para a análise empírica proposta neste trabalho.

O modelo de regressão com efeito threshold pode ser expresso como:

$$
\begin{aligned}
& y_{i}=\theta_{1}^{\prime} x_{i}+e_{i}, \quad q_{i} \leq \gamma \\
& y_{i}=\theta_{2}^{\prime} x_{i}+e_{i}, \quad q_{i}>\gamma
\end{aligned}
$$

no qual $q_{i}$ é a variável threshold, a qual é usada para dividir a amostra em dois grupos que podem ser chamados de classes ou regimes. A variável aleatória $e_{i}$ é o erro de regressão.

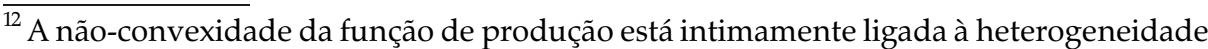
observada entre os municípios, o que leva à possibilidade de existência de múltiplos estados estacionários.
} 
1012 - Determinação dos clubes de convergência da renda per capita agrícola: uma análise para os municípios cearenses

Para escrever o modelo em uma única equação, define-se a variável dummy $d_{i}(\gamma)=I\left\{q_{i} \leq \gamma\right\}$, onde $I\{\}$ é uma função indicadora, e faz-se $x_{i}(\gamma)=x_{i} d_{i}(\gamma)$, tal que:

$y_{i}=\theta_{2}^{\prime} x_{i}+\delta_{n}^{\prime} x_{i}(\gamma)+e_{i}$

em que $\delta_{n}=\theta_{2}-\theta_{1}$.

A equação (9) pode ser representada na forma matricial. Isto é, $Y$ e $e$ são vetores $(n \times 1)$; $X$ e $X_{\gamma}$ matrizes com dimensão $(n \times m)$; então, a equação (9) pode ser escrita como,

$$
Y=X \theta+X_{\gamma} \delta_{n}+e
$$

Os parâmetros da equação acima $\left(\theta, \delta_{n}, \gamma\right)$ podem ser estimados por mínimos quadrados. Definindo $S_{n}(\theta, \delta, \gamma)=\left(Y-X \theta-X_{\gamma} \delta\right)^{\prime}\left(Y-X \theta-X_{\gamma} \delta\right)$, como a função de soma de quadrados dos erros, por definição os estimadores de mínimos quadrados $\hat{\theta}, \hat{\delta}, \hat{\gamma}$, minimizam a soma acima. Neste processo, assume-se que $\gamma$ é restrito a um conjunto limitado $[\gamma, \bar{\gamma}]=\Gamma$.

Condicionando os parâmetros da equação (10) em relação aos valores de $\gamma$, obtém-se os estimadores de mínimos quadrados condicionados, $\hat{\theta}(\gamma)$ e $\hat{\delta}_{n}(\gamma)$, através da regressão de $Y \mathrm{em} X_{\gamma}^{*}=\left[X X_{\gamma}\right]$. Assim, $S_{n}(\theta, \delta, \gamma)$ pode ser escrita na forma concentrada:

$$
S_{n}(\gamma)=S_{n}(\hat{\theta}(\gamma), \hat{\delta}(\gamma), \gamma)=\Upsilon^{\prime} Y-Y^{\prime} X_{\gamma}^{*}\left(X_{\gamma}^{*} X_{\gamma}^{*}\right)^{-1} X_{\gamma}^{*}{ }^{\prime} Y
$$

Para encontrar o valor de $\hat{\gamma}$ que minimiza a equação (9) deve-se realizar uma varredura sobre os valores de $\gamma$; i.e. sobre $\Gamma$, tal que

$$
\hat{\gamma}=\underset{\gamma \in \Gamma_{n}}{\arg \min } S_{n}(\gamma)
$$

no qual $\Gamma_{n}=[\gamma, \bar{\gamma}] \cap\left\{q_{1}, \ldots, q_{n}\right\}$, e $\left\{q_{1}, \ldots, q_{n}\right\}$ é a amostra de variáveis candidatas à variável threshold. Após a determinação de $\hat{\gamma}$, as estimativas de MQO de $\theta$ e $\gamma$, são dadas por $\hat{\theta}=\hat{\theta}^{\prime}(\hat{\gamma})$ e $\hat{\delta}=\hat{\delta}^{\prime}(\hat{\gamma})$.

Em geral, a estimação do intervalo de confiança no modelo threshold é encontrada através da inversão da estatística de Wald ou da estatística $t$. No entanto, como no modelo em questão o parâmetro $\gamma$ não éidentificado, a estatística de Wald tem suas propriedades de pequenas amostras prejudicadas ${ }^{13}$. A estratégia utilizada por Hansen é baseada na estatística de verossimilhança $L R_{n}(\gamma)$.

Para elaborar regiões de confiança baseado em $L R_{n}(\gamma)$, define-se $C$ como o nível de intervalo de confiança assintótico $(C=0,95)$ e $c=c_{\xi}(C)$ como o valor crítico do intervalo $\hat{\Gamma}=\left\{\gamma: L R_{n}(\gamma) \leq c\right\}$.

Observe-se que se a hipótese de homocedasticidade é rejeitada, a estatística de verossimilhança pode ser redefinida como:

$$
L R_{n}^{*}(\gamma)=\frac{L R_{n}(\gamma)}{\hat{\eta}^{2}}=\frac{S_{n}(\gamma)-S_{n}(\hat{\gamma})}{\hat{\sigma}^{2} \hat{\eta}^{2}}
$$

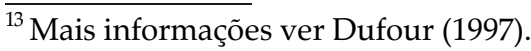




\subsection{O Modelo Econométrico - A Equação de Convergência}

A análise empírica consiste de dois passos. No primeiro, o modelo threshold identifica a existência de múltiplos regimes ou dos clubes de convergência e, no segundo, são estimadas regressões por Mínimos Quadrados Ordinários para cada um dos clubes identificados ${ }^{14}$.

O modelo econométrico é obtido utilizando o mesmo valor de $\lambda_{i}$ para todos os municípios, resultando na seguinte equação para o produto por trabalhador.

$\ln (Y / L)_{i, 1996}-\ln (Y / L)_{i, 1970}=\beta_{0}+\beta_{1} \ln (Y / L)_{i, 1970}+\beta_{2} \ln (\text { capital físico })_{i}+$ $+\beta_{3} \ln (\text { capital humano })_{i}+\beta_{4} \ln (\text { terra })_{i}+\beta_{5} \ln \left(n_{i}+g+\delta\right)+\varepsilon_{i}$

Onde $\varepsilon \sim N\left(0, \Omega_{\varepsilon}\right)$ é o erro da regressão e assume-se, seguindo Mankiw et al. (1992), que $g=0,02$ e $\delta=0,03$. Esta equação será estimada de acordo com o procedimento descrito na seção 4.1.

A evidência de convergência é associada com o sinal negativo para $\beta_{1}$. Ou seja, a convergência ocorre quando economias com produto per capita menor crescem mais rápido que economias com produto per capita maior. Vale salientar, que a taxa de convergência em estado estacionário é dada por $\lambda_{i}=\ln \left(1+\beta_{1}\right) / \tau$.

Os dados utilizados são cross-sections para 141 municípios dos períodos de 1970 e 1996, retirados dos Censos Agrícolas e dos Censos Demográficos do IBGE, coletados junto ao Ipeadata ${ }^{15}$. As variáveis utilizadas são descritas abaixo. Vale ressaltar, também, que o estado do Ceará, segundo o Censo de 2000, possuía 187 municípios. Entretanto, considerando o interesse numa análise desagregada, o que levou à eleição do município como unidade de observação, há uma certa descontinuidade durante o período amostral. Por questões políticoadministrativas foram criados vários municípios entre 1970 e 1996; implicando, desta forma, que a amostra teve que ser reduzida para 141 municípios, uma vez que 46 municípios que não existiam em 1970 foram excluídos.

Quanto às variáveis utilizadas, estas são descritas a seguir:

i. $(Y / L)_{i, t}=$ Foi utilizado como proxy para a renda per capita agrícola o valor da produção agropecuária total divido pelo total do pessoal ocupado no meio rural para o município $i$, no ano $t=1970,1996$. O valor da produção da agropecuária exclui a indústria rural e os valores estão em milhares de reais de 2000, corrigidos pelo deflator implícito do PIB nacional;

ii. (capital físico $)_{i, 1996}=$ Foi utilizado como proxy para capital físico, o valor médio dos bens agropecuários no período de 1970 a 1985, dividido pelo número total de estabelecimentos rurais no ano de 1996 para o município

\footnotetext{
${ }^{14}$ Foram empregadas estimações com correções para heterocedasticidade. Mais informações ver Durlauf e Johnson (1995).

${ }^{15}$ Ver www.ipea.gov.br .
} 
1014 - Determinação dos clubes de convergência da renda per capita agrícola: uma análise para os municípios cearenses

i. Os valores dos bens agropecuários estão em milhares de reais de 2000, também corrigidos pelo deflator implícito do PIB nacional;

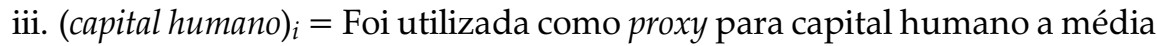
de anos de estudo para o período de 1970 a 2000 do município $i$. Compreende os anos de estudo de pessoas com 25 anos e mais;

iv. $(n)_{i}=$ Compreende a taxa de crescimento média do pessoal ocupado no meio rural durante 1970 e 1996 do município $i$;

v. $(\text { terra })_{i}=$ Foi utilizado como proxy para terra, uma medida de hectares per capita utilizados na agropecuária no período de análise. A variável foi construída, dividindo a área média total dos estabelecimentos em hectares no período de 1970 a 1996, pelo número médio de estabelecimentos rurais do município $i$

\section{Resultados Empíricos}

A variável renda agrícola per capita 1970 foi considerada como candidata à variável threshold do modelo. Evidências para o efeito threshold são obtidas usando o teste de Multiplicador de Lagrange com correção para heterocedasticidade, como descrito anteriormente. $O$ procedimento consiste em verificar se existe evidência para o efeito threshold, considerando a hipótese nula de inexistência e computando os p-valores via bootstrap.

$\mathrm{O}$ teste para efeito threshold foi aplicado de forma interativa até não haver mais evidência estatística da necessidade de novas subdivisões amostrais. A Tabela 2 sumariza os resultados encontrados para a divisão da amostra entre os nós de decisão. Esta contém a identificação de cada nó, os valores da estatística LM, o valor threshold e o intervalo de confiança. Os resultados revelam a existência de três nós de decisão e de quatro nós terminais, ou clubes de convergência. Os nós de decisão correspondem ao nó inicial, um na primeira interação (1.1) e um na segunda interação (2.1). Desta forma, de acordo com o exposto acima, pode-se concluir pela existência de quatro grupos com características socioeconômicas distintas $(1.2 ; 2.2 ; 3.1 ; 3.2)$.

Tabela 2. Decisão de divisão da amostra

\begin{tabular}{cccc}
\hline \multirow{2}{*}{ Nó de Decisão } & Teste LM & \multicolumn{2}{c}{ Decisão de Divisão } \\
\cline { 2 - 4 } & VProd70 & Valor threshold & $\begin{array}{c}\text { Intervalo de } \\
\text { Confiança }\end{array}$ \\
\hline Vprod & 13.89 & 7.600 & {$[7.600,7.114]$} \\
1.1 & 15.59 & 6.997 & {$[6.530,7.243]$} \\
2.1 & 14.320 & 6.597 & {$[6.560,6.650]$} \\
\hline
\end{tabular}

Nível de significância utilizado foi de 95\% e H0: não há divisão da amostra.

Fonte: Elaboração dos autores. 
Para melhor visualização, foi elaborado um diagrama de árvore que contém os nós de decisão e os nós terminais. Nele, os quadrados representam os nós de decisão e os triângulos representam os nós terminais, ou clubes de convergência. As informações em cada quadrado representam a identificação do nó e o número de municípios contidos nele. Já o valor threshold é disposto nos braços que saem de cada nó. Similarmente, a informação dentro do nó terminal representa sua identificação e o número de municípios contidos em cada um deles. Ressalta-se que o lado esquerdo de cada nó de decisão contém as observações no qual a variável é menor ou igual ao valor threshold (Figura 8).

Figura 8. Diagrama de decisão do efeito threshold

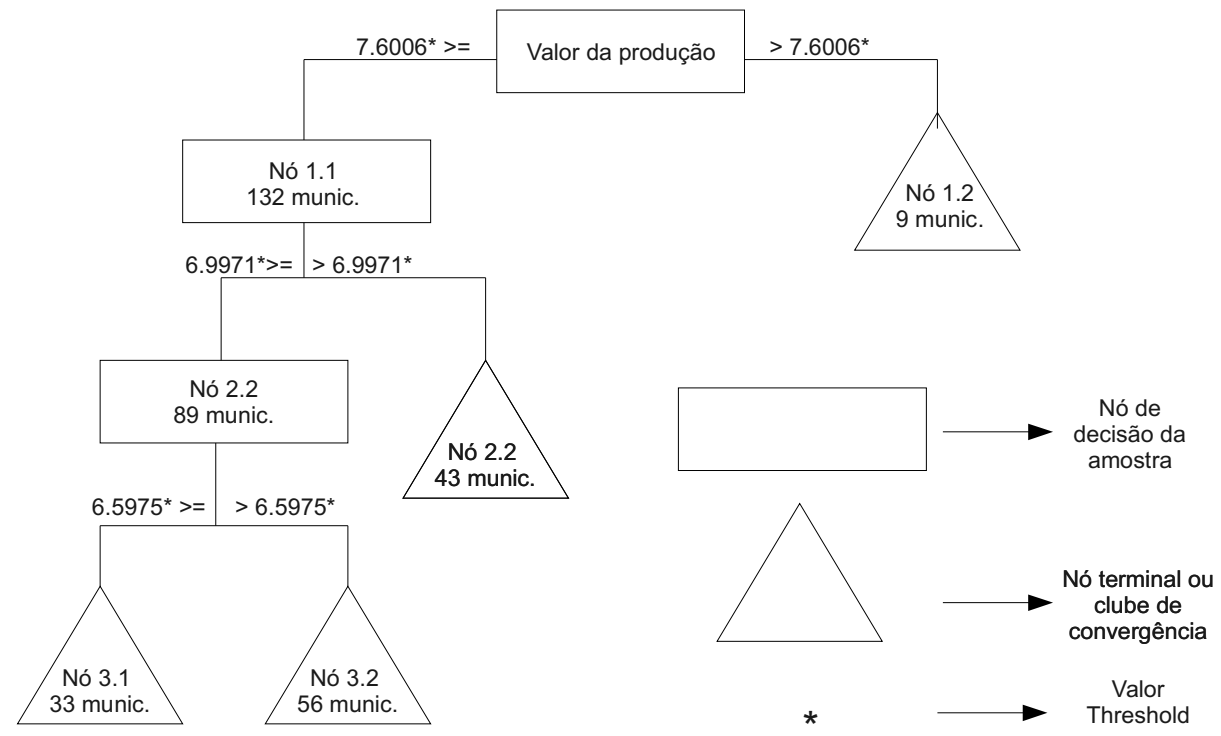

Fonte: Elaboração dos autores.

O clube 3.1, correspondente ao clube mais pobre, abrange os 33 municípios com renda agrícola per capita inferior a $\mathrm{R} \$ 733,25$. O nó 3.2 corresponde a um clube de convergência intermediário com 56 municípios que possuem a renda agrícola per capita entre $\mathrm{R} \$ 733,25$ e $\mathrm{R}$ \$ 1093,45. O nó terminal 2.2 corresponde ao segundo clube intermediário, com 43 municípios que possuem a renda agrícola per capita entre R\$1093,45 e R\$1999,39. Por fim, tem-se o clube de convergência 1.2 que corresponde ao clube mais rico, compreendendo os 9 municípios que possuem a renda agrícola per capita superior a $\mathrm{R} \$ 1999,39^{16}$.

\footnotetext{
${ }^{16}$ Esse valor é derivado da aplicação do antilog no valor threshold correspondente a cada nó terminal.
} 
1016 - Determinação dos clubes de convergência da renda per capita agrícola: uma análise para os municípios cearenses

\subsection{Análise Intra-Clubes}

A Tabela 3 apresenta os resultados de MQO para cada um dos cinco nós terminais e para a amostra total, ou seja, para todo o estado do Ceará.

Observa-se que, quando se considera a amostra total, o coeficiente do logaritmo da renda agrícola per capita dos municípios apresenta-se significante e com sinal negativo, indicando que existe convergência entre os mesmos. E ainda, o capital físico, o capital humano e a tecnologia mostraram-se significantes. Já em relação à terra, esta não se mostrou importante para explicar o processo de convergência, considerando a amostra global.

Ao analisar os nós terminais, observa-se a formação de quatro clubes de convergência bem distintos. O grupo 1.2 é o grupo de municípios com maior renda agrícola per capita; o grupo 3.1 é o grupo com menor renda agrícola per capita; já os grupos 2.2 e 3.2 são os clubes com renda intermediária.

Observando os resultados para o clube com maior renda agrícola per capita (superior a R \$1999,39 (1.2)), constata-se a existência de convergência dentro deste grupo, bem como é possível observar que o capital físico, o capital humano, a terra e a tecnologia se mostraram importantes para explicar o referido processo.

Tabela 3. Análise de regressão de MQO

\begin{tabular}{lccccc}
\hline \multirow{2}{*}{ Municípios } & Ceará & Clube 1.2 & Clube 2.2 & Clube 3.2 & Clube 3.1 \\
\cline { 2 - 6 } & $\mathbf{1 4 1}$ & $\mathbf{9}$ & $\mathbf{4 3}$ & 56 & 33 \\
\hline Constante & $3.679^{*}$ & $33.601^{*}$ & -0.734 & $7.112^{*}$ & $4.685^{*}$ \\
& $(1.118)$ & $(5.083)$ & $(3.648)$ & $(2.948)$ & $(1.296)$ \\
$\ln (\text { renda agrícola })_{1970}$ & $-0.839^{*}$ & $-6.228^{*}$ & -0.129 & $-1.281^{*}$ & $-1.395^{*}$ \\
& $(0.094)$ & $(0.723)$ & $(0.403)$ & $(0.421)$ & $(0.177)$ \\
$\ln ($ capital físico) & $0.151^{*}$ & $1.314^{*}$ & $0.105^{*}$ & $0.099^{* *}$ & $0.190^{*}$ \\
& $(0.048)$ & $(0.103)$ & $(0.030)$ & $(0.050)$ & $(0.053)$ \\
$\ln ($ capital humano) & $0.903^{*}$ & $1.984^{*}$ & $0.994^{*}$ & $0.934^{*}$ & $0.503^{*}$ \\
& $(0.195)$ & $(0.303)$ & $(0.334)$ & $(0.241)$ & $(0.197)$ \\
$\ln \left(n_{i}+g+\delta\right)$ & $-0.251^{*}$ & $1.700^{*}$ & $-0.141^{* *}$ & $-0.346^{*}$ & $-0.521^{*}$ \\
& $(0.097)$ & $(0.256)$ & $(0.080)$ & $(0.101)$ & $(0.108)$ \\
$\ln ($ terra $)$ & 0.041 & $0.474^{*}$ & 0.138 & 0.120 & 0.137 \\
$R^{2}$ ajustado & $(0.082)$ & $(0.153)$ & $(0.149)$ & $(0.083)$ & $(0.102)$ \\
Resíduo de Variância & 0.49 & 0.97 & 0.41 & 0.47 & 0.83 \\
\hline
\end{tabular}

Obs: * significantes a 5\%; ** significantes a 10\%; Valores entre parênteses são os desvios-padrão.

Fonte: Elaboração dos autores. 
Com relação ao clube com menor renda agrícola per capita (inferior a $\mathrm{R} \$ 733,25$ (3.1)), nota-se que o processo de convergência se manifesta e que o capital físico e o capital humano mostraram-se importantes na explicação do crescimento desses municípios; entretanto, a terra e a tecnologia foram insignificantes. Dada às condições socioeconômicas precárias deste clube, os resultados comprovam as expectativas preliminares de que tanto o capital físico quanto o capital humano fossem importantes para explicar o seu processo de crescimento, o que também era esperado para a dotação de terra.

Os resultados do clube com renda agrícola per capita intermediária (3.2), dentro do intervalo de $\mathrm{R} \$ 733,25$ e $\mathrm{R} \$ 1093,45$, mostraram a existência de convergência entre os municípios, bem como que o capital físico, o capital humano e a tecnologia mostram-se importantes no processo de convergência do clube, porém, a terra não se mostrou expressiva.

Em relação ao clube (2.2), que se situa dentro do intervalo de R\$1.093,45 e R\$ $1.999,39$, os resultados apresentados na Tabela 3 são dúbios no que se refere à existência de um processo de convergência neste grupo de municípios. Apesar do coeficiente do logaritmo da renda agrícola per capita do período inicial apresentar sinal negativo indicando a existência de convergência, o mesmo não é estatisticamente significante aos níveis usuais. Neste clube, os parâmetros do capital físico, do capital humano e da tecnologia foram significantes, porém, o coeficiente da terra não apresenta significância estatística. Essa ausência de definição quanto ao processo de convergência ou divergência pode estar indicando que os municípios pertencentes a este clube estão em transição e podem, posteriormente, migrar para outros clubes ou mesmo formar outros.

A Figura 9 traz a dispersão dos municípios, levando-se em consideração a classificação dos quatro clubes de convergência, bem como mostra os contornos para as microrregiões estaduais. Nesta Figura, observa-se que os municípios pertencentes ao clube de convergência mais pobre concentram-se na região Norte e Centro Oeste do estado, principalmente, nas microrregiões de Coreaú, Meruoca, Santa Quitéria, Sertão de Crateús e Litoral do Aracati; o que atesta os resultados preliminares encontrados sobre os seus indicadores sociais. Quanto aos outros clubes, estes apresentam os municípios dispersos por todo o espaço geográfico do estado.

Considerando todas as regressões, verifica-se que tanto o capital humano quanto o capita físico mostraram-se significantes para explicar o processo de crescimento dos municípios cearenses. Entretanto, a proxy utilizada para terra foi significante apenas para os dois clubes de maiores renda.

Estes resultados corroboram as evidências encontradas por Barreto e Almeida (2008), onde os autores estudaram o papel do capital humano para o crescimento econômico e a convergência de renda dos municípios do Ceará no período de 1996 a 2003. Através do uso de um modelo de efeitos fixos com dependência espacial, esses autores comprovaram a existência de convergência condicional, bem como encontraram que o crescimento do PIB per capita foi afetado negativamente pela variável densidade demográfica e, positivamente, pelas variáveis capital humano, infra-estrutura, capital social, mercado regional e externalidades espaciais. 
1018 - Determinação dos clubes de convergência da renda per capita agrícola: uma análise para os municípios cearenses

Figura 9. Dispersão espacial dos municípios cearenses de acordo com a classificação dos clubes de convergência

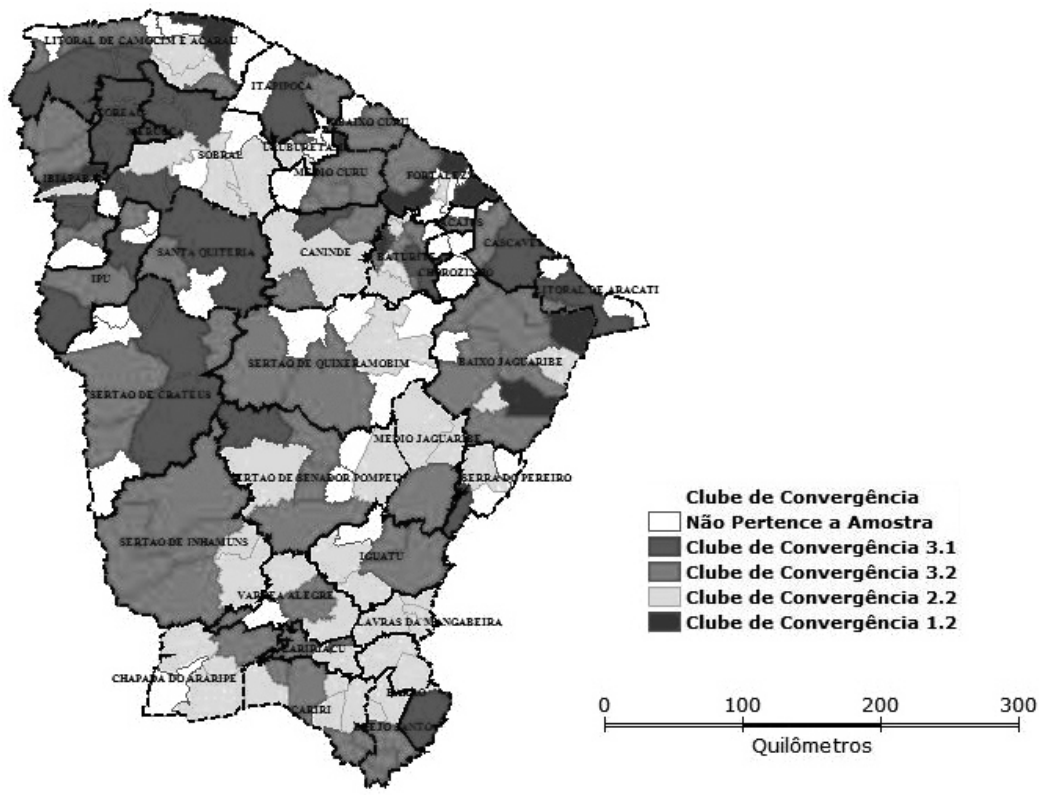

Fonte: Elaboração dos autores.

Os resultados obtidos por Lau et al. (2003) que estudaram o papel do capital humano no crescimento econômico do setor agrícola brasileiro em 1970, 1975 e 1980, mostram significância para o capital humano, encontrando uma elasticidade de 0,21 para o mesmo.

Já o estudo de Freitas e Bacha (2004), que estimou a contribuição do capital humano para o setor agrícola no período entre 1970 e 1996, para os estados brasileiros, encontrou que o capital humano é relevante; no entanto, o capital físico não foi significante. Vale ressaltar que quando estes autores utilizam o efeito threshold para mensurar a contribuição do capital humano, este se mostra insignificante.

Já para o insumo terra, os resultados encontrados nesse estudo podem ser explicados pela grande concentração fundiária no estado. Conforme Souza e Lima (2003), os resultados para o índice de Gini para a terra concluem que o estado do Ceará apresenta a distribuição da terra com característica de concentração forte a muito forte. 


\section{Conclusão}

Este trabalho teve como objetivo investigar a existência de um processo de convergência do PIB agrícola entre os municípios do Ceará, levando em consideração a possibilidade de existência de grupos de municípios com características diferentes.

Os resultados mostraram que a hipótese de grupos de municípios com características socioeconômicas diferentes foi comprovada, indicando a existência de quatro clubes de convergência. Já dentro dos clubes de convergência, os resultados mostraram que a hipótese de convergência verifica-se dentro de três dos quatro clubes.

Os resultados também mostraram que o capital humano parece influenciar mais o processo de crescimento dos municípios do que o capital físico, que só foi significante em três clubes. Os resultados aqui encontrados para o capital humano corroboram os resultados de Freitas e Bacha (2004), que também encontraram evidências fortes para importância do capital humano no processo de crescimento.

Pode-se observar ainda que os municípios que apresentaram os piores indicadores sociais como, por exemplo, anos de educação, foram aqueles que formaram o clube de convergência com menor renda per capita. Já os demais clubes são compostos por municípios dispersos por todo o espaço geográfico do estado.

\section{Referências Bibliográficas}

ALENCAR, Fredrico A. Gomes. Searching for Socioeconomic Patterns in the Brazilian Municipalities. An Analysis of Clube Convergence. Texto para Discussão, 2005.

ALMEIDA, M. B.; CASTELAR, I.; CARVALHO JÚNIOR, J. R. A. e FRANÇA, J. M. S., Padrões de â-convergência e ó-convergência: Uma Análise da Indústria Brasileira. Revista Econômica do Nordeste, Fortaleza, v28, pp. 275-288, 1997.

ARRAES, R. de A. Hipótese de Convergência da Renda per capita e da Produtividade Setorial para o Nordeste. Fortaleza, CAEN/UFC, Texto para Discussão, 1997.

AZARIADIS, C. e DRAZEN, A. Threshold Externalities in Economic Development,.Quarterly Journal of Economics, vol.105, no.2, pp. 501-526, 1990.

BENHABIB, J. E SPIEGEL, M. The Role of Human Capital in Economic Development: Evidence from Aggregate Cross-Country Data. Journal of Monetary Economics, 34 (2):143-174, 1994. 
1020 - Determinação dos clubes de convergência da renda per capita agrícola: uma análise para os municípios cearenses

BREIMAN, L., FRIEDMAN, J. L., OLSHEN, R.A. e STONE, C.J., Classification and Regression Tress, Wadsworth, Belmont, CA, 1984.

BRUM, Argemiro Jr. Desenvolvimento Econômico Brasileiro. 23ª Edição, Editora Vozes, 569p, 2003.

CÂMARA, L. A Concentração da Propriedade Agrária no Brasil. Boletim Geográfico, Rio de Janeiro, v. 7, n.77, pp. 516-528, ago.,

DESDOIGTS, A., Patterns of Economic Development and the Formation Clubs, Journal of Economic Growth, vol.4, n3, pp. 305-30, 1999.

DUALAUF, S. N., KOURTELLOS, A. e MINKIN, A., The Local Solow Growth Model, European Economic Review, vol. 45, n4-6, pp. 928940, 2001.

DUFOUR, Jean-Marie., Some Impossibility Theorems in Econometrics with Applications to Structural and Dynamic Models. Econometrica, 65, pp. 1365-1388, 1997.

DURLAUF, S. N. e JOHNSON, P., Multiple Regimes and Cross-Country Growth Behaviour, Journal of Applied Econometrics, vol. 10, n4, pp. 365-384, 1995.

FREITAS, C. A. e BACHA, C. J. C. Contribuição do Capital Humano para o Crescimento da Agropecuária Brasileira - Período de 1970 a 1996. Revista Brasileira de Economia, 58 (4), pp. 533-557, out/dez, 2004

GALOR, O., Convergece? Inferences from Theoretical Models, Economic Journal, vol. 106, n437, pp. 1056-1069, 1996.

HANSEN, B. E., Sample Splitting and Threshold Estimation, Econometrica, vol. 68, n3, pp.575-603, 2000.

HANUSHEK, E. A. e KIMKO, D. D. Schooling, Labor-Force Quality, and Gowth of Nations. American Economic Review, 90(5):1184-208, 2000.

HOFFMANN, R. Estatística para Economistas. 2. ed. São Paulo: Livraria Pioneira Editora. 1991. 426p.

JONES, C.I., On the Evolution of World Income Distribuition. Journal of Economic Perspectives, vol. 11, n3, pp.19-36, 1997.

KRUEGER, A. B.; LINDAHL, M. Education for Growth: Why and for Whom? Journal of Economic Literature, 39(4):1101-1136, 2001.

LAU, L. J.; JAMISON, D. T.; LIU, S. e RIVKIN, S. Education and Economic Growth: Some Cross-Sectional Evidence from Brazil Journal of Development Economics, 41, pp. 45-70, 1993.

LUCAS, R. On the Mechanics of Economic Development, Journal of Monetary Economics, 22, pp.3-42, 1988. 
MANKIW, N. G., D., ROMER, e D. WEIL, A Contribution to the Empirics of Economic Growth, Quarterly Journal of Economics, vol. 107, n2, pp. 407-437, 1992.

OLIVEIRA JUNIOR, J. N; CASTELAR, I.; FERREIRA, R. T. Convergência Microrregional no Setor Agrícola usando um Modelo Threshold, 2007. Disponível em:<http://www.anpec.org.br/encontro2007/artigos/A07A123.pdf> Acesso em 3 jan 2008.

PRITCHETT, L. Divergence, Big Time. Journal of Economic Pespectives, vol.11, n3, pp.3-17, 1997.

QUAH, D. Twin Peaks: Growth and Convergence in Models of Distributions Dynamics, Economic Journal, vol. 106, n437, pp.1045-1055, 1996.

, Empirics for Growth and Distribution: Stratification, Polarization and Convergence Clubs. Journal of Economic Growth, 2(1):27-59, march, 1997.

REPPAPROT, J., Local Growth Empirics, Center for International Development at Harvard University - CID Working Paper n 23, 1999.

ROMER, P. Increasing Returns and Long Run Growth. Journal of Political Economy, Octuber, 1986.

SOBRERIA, C.E.P., SOARES, R.B., FILHO, A. B. e TEIXEIRA, R. M. G. Gastos Públicos Na Agricultura Brasil - Ceará. Texto para Discussão, n 19, IPECE, 2005.

SOUZA, Paulo Marcelo.; LIMA, João Eustáquio de, A Distribuição da Terra no Brasil e nas Unidades da Federação, 1970 - 95/96. Revista de Economia do Nordeste, Fortaleza, v. 34, n.1, jan-mar. 2003.

WOLF, E. N. Human Capital Investment and Economic Growth: Exploring Cross CountryEvidence. Structural Change and Economic Dynamics, 11(4):433-472, 2000. 